\title{
EVALUATION OF THE IMPORTANCE OF THE 39 SUBJECTS DEFINED BY THE GLOBAL FORUM FOR MAINTENANCE AND ASSET MANAGEMENT
}

\author{
J.K. Visser ${ }^{1 *} \&$ T.A. Botha ${ }^{2}$ \\ Department of Engineering and Technology Management \\ University of Pretoria, South Africa \\ ${ }^{1}$ krige.visser@up.ac.za, 2arnold.botha@pragmaworld.com
}

\begin{abstract}
The Global Forum on Maintenance and Asset Management (GFMAM) was formed in 2011 to bring together various experts, practitioners, academics, and other professionals who are active in the field of asset and maintenance management. The primary mission of GFMAM is to develop and promote knowledge, standards, and education for the maintenance and asset management professions. To fulfil this mission, GFMAM developed an 'Asset Management Landscape' document, which defines 39 subjects on asset management, grouped into six main subject areas.
\end{abstract}

This paper reports on two surveys that were conducted to determine the importance of the 39 asset management subjects. Respondents were requested to rate the importance of each of the 39 subjects on a five-point scale. Results from the survey indicated that the five most important subjects are 'asset management strategy and objectives', 'asset management policy', 'strategic planning', 'asset management planning', and 'asset management leadership'.

\section{OPSOMMING}

Die 'Global Forum on Maintenance and Asset Management' (GFMAM) is in 2011 gestig om verskeie kundiges, praktisyns, akademici, en ander professionele persone wat betrokke is in die kundigheidsarea van bate- en instandhoudingsbestuur met mekaar in kontak te bring. Die hoofdoelwit van GFMAM is om kennis, standaarde, en opleiding te bevorder in die instandhouding- en batebestuursprofessies. Ten einde hierdie doelwit te bereik het die GFMAM 'n batebestuur landskap dokument ontwikkel. Die dokument bevat 'n lys van 39 kundigheidsareas wat in ses hoof onderwerpareas gegroepeer is.

Hierdie artikel bespreek die resultate van twee opnames wat uitgevoer is om die belangrikheid van die 39 kundigheidsareas te bepaal. Respondente is versoek om die belangrikehid van elk van die 39 areas te verskaf op 'n 5-punt skaal. Volgens die opname is die vyf belangrikste onderwerpareas 'batebestuur strategie en doelwitte', 'batebestuur beleid', 'strategiese beplanning', 'batebestuur beplanning', en 'batebestuur leierskap'. 


\subsection{Background}

The Global Forum on Maintenance and Asset Management (GFMAM) was formed in 2011 to bring together various experts, practitioners, academics, and other professionals who are active in the field of maintenance and asset management. Early in the organisation's history, it was found that the area of asset management is not well-defined or demarcated. A need was expressed to develop a document that would summarise the basic principles of asset management and define the knowledge areas or subjects that describe this field. So the 'landscape' project was launched; its main purpose was "to provide a framework and define the content, principles and guidelines for asset management" [1]. Version 1 of the asset management landscape was released in 2011, whereas Version 2 was only released early in 2014. Version 2 was intended as a "framework to enable asset management knowledge and practices to be compared, contrasted and aligned around a common understanding of the discipline of asset management" [1].

This paper discusses a research project that investigated the importance of the 39 subjects as presented in "The Asset Management Landscape" (version 1 and 2). A survey based on Version 1 of the landscape document was conducted in the latter half of 2013; a similar survey was performed with a different population when Version 2 was released in 2014.

\subsection{Research objectives}

This research project had two main objectives:

- to determine the importance of each of the 39 subjects as viewed by asset management and maintenance management practitioners; and

- to determine whether age, experience, and job description have an effect on the importance rating of the 39 subjects.

\subsection{Importance of the topic}

Many educational institutions around the world are developing educational programmes on asset management. It is recognised that asset management is a very diverse knowledge area, and many curricula do not include all 39 subjects in their postgraduate or continuing education programmes. The outputs of this project could provide some guidance about which subjects should be included in the curricula of asset management programmes.

\section{LITERATURE}

\subsection{Frameworks and models}

While there are many international frameworks and models for other operational disciplines, such as quality management [2,3], safety [4], environment [5], and even risk management [6], the maintenance and asset management disciplines lacked such frameworks until recently. As a result, a variety of publications and consultants have proposed different models, definitions, and frameworks to provide practitioners with a way to understand these complex yet important topics.

\subsection{Frameworks for maintenance management}

In the literature, several frameworks and models for maintenance management have been proposed over the years. The most important of these are:

- the 'EUT maintenance model' developed by Geraerds [7] of Eindhoven University, which distinguished between a technical maintenance system and a management system for maintenance;

- the 'maintenance management framework' by Marques [8], which provides a very comprehensive and useful model for maintenance, including technical failure analysis, 
the development of maintenance tactics (RCM), planning and scheduling, and maintenance strategies.

- Visser's [9] developed a conceptual framework for understanding and teaching maintenance, in order to address the need to teach maintenance management at academic institutions.

For a more detailed review of these models, refer to Visser's paper [9]. However, the only maintenance management framework that has received widespread international acceptance and adoption is the International Infrastructure Maintenance Manual (IIMM) [10], which is used widely in the civil engineering industry.

\subsection{Frameworks for asset management}

'Asset management' is a term that has only been defined recently to address all activities during the life of an asset, from acquisition to operations and maintenance to decommissioning. An asset is defined in ISO 55000 [11] as "an item, thing or entity that has potential or actual value to an organization". Asset management is defined in ISO 55000 [11] as the "coordinated activities of an organisation to realize value from assets".

While maintenance management is a much more mature concept, with a variety of models and frameworks, asset management is less mature. The first real effort to develop a comprehensive framework for asset management was the publically available specification, PAS 55 [12], developed by the UK-based Institute for Asset Management (IAM) and published by the British Standards Institute (BSI). This framework provided a clear definition of asset management and an asset management system, with 24 elements grouped together according to Deming's Plan-Do-Check-Act (PDCA), or more correctly the Plan-Do-Study-Act (PDSA), cycle [13].

PAS 55 was supplemented later by another document from IAM called Asset Management: An Anatomy [14], which provided a more detailed description of asset management activities, as opposed to PAS 55's definition of an asset management system. PAS 55 and the Asset Management Anatomy document were adopted in certain countries outside of the UK, but they did not receive international acceptance.

The Australian Asset Management Council (AMC) also compiled the Asset Management Body of Knowledge (AMBoK) [15] as a comprehensive asset management framework, which was supplemented by best practices. The most recent version was released in April 2014.

ISO 55001 [5] was released in January 2014, and became the first internationally-accepted standard for an asset management system, which is a subset of the wider discipline of asset management, as depicted in Figure 1.

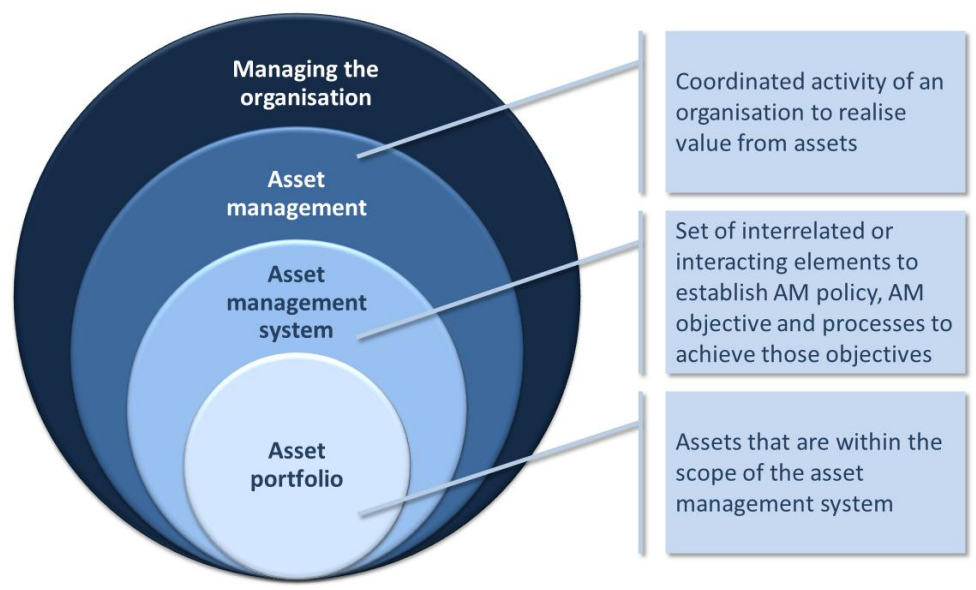

Figure 1: Difference between asset management and an asset management system [5] 
The first internationally-accepted framework for asset management was the Asset Management Landscape with its 39 subjects, which was first released in 2011. This framework is discussed in the next section.

\section{THE GLOBAL FORUM ON MAINTENANCE AND ASSET MANAGEMENT (GFMAM)}

\subsection{Vision and mission}

GFMAM's vision is to "be a worldwide community of organisations providing leadership for maintenance and asset management communities" [1].

The mission of GFMAM was formulated in 2011 to:

- develop and promote knowledge, standards, and education for the maintenance and asset management professions; and

- collaborate on the development and means to share advancements, knowledge, and standards in maintenance and asset management.

\subsection{The Landscape documents}

One of GFMAM's projects was to develop a framework comprising principles and guidelines for asset management. The result was a document called the Asset Management Landscape [1], which was released in 2011 and which contained:

- $\quad$ six principles of asset management; and

- 39 asset management subjects (or elements), grouped into six areas.

The Landscape document was accepted by all its member associations, and it was agreed that:

- all endorsed asset management competency frameworks, training courses, and qualifications will be aligned with the 39 subjects; and

- $\quad$ all endorsed asset management maturity assessments and awards will be aligned with those 39 subjects.

It is therefore clear that the 39 subjects are very important for all asset management practitioners, training providers, service providers, and academic institutions.

The Landscape document was updated with the release of its second version in April 2014. The list of 39 subjects was changed slightly, with some subjects renamed and some replaced by others. In addition, the new version contains a page-long summarised description for each subject.

\subsection{The 39 subjects}

The asset management subjects for the Landscape 1 and Landscape 2 documents are listed in Table 1. The numbers of the subjects are given as cross references to interpret the results in Section 4.

Table 1: Subjects of the Landscape 1 (2011) and Landscape 2 (2014) documents [1]

\begin{tabular}{|l|l|l|l|}
\hline No. & \multicolumn{1}{|c|}{ Subjects in Landscape 1 } & No. & \multicolumn{1}{|c|}{ Subjects in Landscape 2 } \\
\hline 1 & Asset management policy & 1 & Asset management policy \\
\hline 2 & Asset management strategy & 2 & $\begin{array}{l}\text { Asset management strategy and } \\
\text { objectives }\end{array}$ \\
\hline 3 & Demand analysis & 3 & Demand analysis \\
\hline 4 & Strategic planning & 4 & Strategic planning \\
\hline 5 & Asset management plan & 5 & Asset management planning \\
\hline 6 & Capital investment decision-making & 6 & Capital investment decision-making \\
\hline
\end{tabular}




\begin{tabular}{|c|c|c|c|}
\hline No. & Subjects in Landscape 1 & No. & Subjects in Landscape 2 \\
\hline 7 & Operations and maintenance decision-making & 7 & $\begin{array}{l}\text { Operations and maintenance decision- } \\
\text { making }\end{array}$ \\
\hline 8 & Whole-life cost and value optimisation & 8 & Lifecycle value realisation \\
\hline 9 & Resourcing strategy and optimisation & 9 & Resourcing strategy \\
\hline 10 & Shutdowns, outage strategy, and optimisation & 10 & Shutdowns and outage strategy \\
\hline 11 & Aging assets strategy & 11 & Technical standards and legislation \\
\hline 12 & Technical standards and legislation & 12 & Asset creation and acquisition \\
\hline 13 & Asset acquisition and commissioning & 13 & Systems engineering \\
\hline 14 & Systems engineering & 14 & Configuration management \\
\hline 15 & Configuration management & 15 & Maintenance delivery \\
\hline 16 & Maintenance delivery & 16 & Reliability engineering \\
\hline 17 & Reliability engineering & 17 & Asset operations \\
\hline 18 & Asset operations & 18 & Resource management \\
\hline 19 & Resource management & 19 & Shutdown and outage management \\
\hline 20 & Shutdown and outage management & 20 & Fault and incident response \\
\hline 21 & Fault and incident response & 21 & Asset decommissioning and disposal \\
\hline 22 & Asset rationalisation and disposal & 22 & Asset information strategy \\
\hline 23 & Asset information strategy & 23 & Asset information standards \\
\hline 24 & Asset knowledge standards & 24 & Asset information systems \\
\hline 25 & Asset information systems & 25 & Data and information management \\
\hline 26 & Asset data and knowledge & 26 & $\begin{array}{l}\text { Procurement and supply chain } \\
\text { management }\end{array}$ \\
\hline 27 & Contract and supplier management & 27 & Asset management leadership \\
\hline 28 & Asset management leadership & 28 & Organisational structure \\
\hline 29 & Organisational structure and culture & 29 & Organisational culture \\
\hline 30 & Competence and behaviour & 30 & Competence management \\
\hline 31 & Criticality, risk assessment, and management & 31 & Risk assessment and management \\
\hline 32 & Contingency planning and resilience analysis & 32 & $\begin{array}{l}\text { Contingency planning and resilience } \\
\text { analysis }\end{array}$ \\
\hline 33 & Sustainable development & 33 & Sustainable development \\
\hline 34 & Weather and climate change & 34 & Management of change \\
\hline 35 & Asset and systems change management & 35 & $\begin{array}{l}\text { Assets performance and health } \\
\text { monitoring }\end{array}$ \\
\hline 36 & $\begin{array}{l}\text { Assets, systems performance, and health } \\
\text { monitoring }\end{array}$ & 36 & Asset management system monitoring \\
\hline 37 & Management review, audit, and assurance & 37 & $\begin{array}{l}\text { Management review, audit, and } \\
\text { assurance }\end{array}$ \\
\hline 38 & Accounting practices & 38 & Asset costing and valuation \\
\hline 39 & Stakeholder relations & 39 & Stakeholder engagement \\
\hline
\end{tabular}

\section{METHODOLOGY}

\subsection{Overview}

The 39 asset management subjects identified by GFMAM provide a useful range of knowledge areas that asset managers would need in order to perform their normal functions. However, some of these knowledge areas would be more important for specific 
positions or functions within the organisation. A first survey comprising the 39 subjects of the Landscape 1 document was therefore developed in 2013. Questionnaires were distributed to about 70 postgraduate students who were enrolled for the Masters in Engineering Management degree at the Graduate School of Technology Management at the University of Pretoria, South Africa. These students take a compulsory course in Maintenance Management, and they can enrol for an elective course in Asset Management in the second year of their Master's programme.

Another group of part-time students who were enrolled for an Honours degree in the Management of Technology were also targeted by the questionnaire, but only those students enrolled for the maintenance management course were selected. Respondents were also requested to indicate some biographical data, such as age, experience in maintenance or operations, and their designation in a company and industry.

After the release of the Landscape 2 document in 2014, a second survey was performed. The target group for this survey was also the postgraduate students enrolled in the Masters in Engineering Management degree at the University of Pretoria. Fifty useful questionnaires were received from this group.

\subsection{Questionnaires}

The ISO 55000 definitions for an 'asset', 'asset management' and 'asset management system' were provided in the first part of the questionnaire. The following comment, which was provided in the ISO 55000 document, was also given to indicate the broader view of asset management [11]:

"This broader view of Asset Management encompasses all asset types, tangible and intangible, individual components or complex systems, and all activities involved in the asset's life cycle - everything from initial identification of requirements or opportunities, acquisition/creation, operations or utilization activities, asset stewardship or care/maintenance responsibilities, through to renewal or disposal and any remaining liabilities. Asset management is therefore holistic - it considers the whole picture rather than just individual contributions."

The first five questions of the two surveys were related to the demographic data of the respondent: age, experience in maintenance or asset management, job level in the company, industry sector, and function description. In the first survey, Question 6 asked respondents to indicate their agreement with the statements related to the six subject groups. This question was not included in the second survey.

The last question requested respondents to indicate how important they viewed each one of the 39 subjects on a five-point scale. The specific question asked in both surveys was:

"Rate the importance of each of the following 39 subjects, defined in GFMAM's Landscape 2 document, on a scale of $1-5$, where $1=$ unimportant, 2 = slightly important, $3=$ moderately important, 4 = very important, and 5 = extremely important."

Definitions of each of the 39 subjects, as given in the Landscape 1 and 2 documents, were also provided in the questionnaire. As an example, the definition for Subject 1, 'asset management policy', is:

"the principles and mandated requirements derived from and consistent with the organisational/corporate plan, providing a framework for the development and implementation of the asset management strategic plan and the setting of the asset management objectives."

The subjects were presented in the same sequence in the questionnaire as indicated in Table 1 above. 


\subsection{Distribution of surveys}

The questionnaires for the first survey were distributed to 118 part-time students of the Graduate School of Technology Management at the University of Pretoria. After eliminating incomplete forms, a total of 110 questionnaires were suitable for use in the analysis of the data.

The questionnaires for the second survey were distributed to 70 students who were enrolled for their first year of the Master's degree in Engineering Management, after they had completed a course in Maintenance Management. Fifty completed questionnaires were received. A number of questionnaires were also distributed to personnel, mostly managers and engineers, in a company that provides asset management and maintenance management services. Thirteen completed questionnaires were received from this group. In total, 63 useful questionnaires were received from the second survey.

\subsection{Age of the respondents}

The age distribution of the respondents of both surveys is shown in Figure 2 below.

\section{—Survey 1 aSurvey 2}

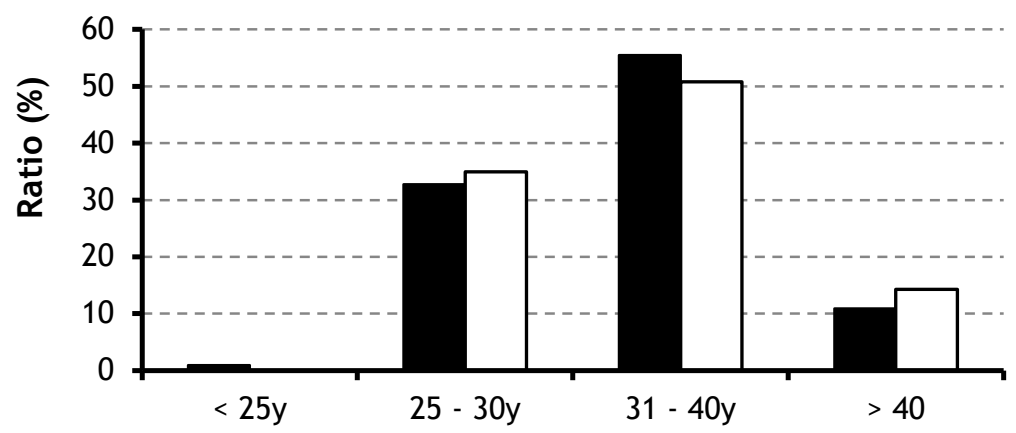

Figure 2: Age distribution of respondents

As seen in Figure 2, the age distributions for the two surveys were fairly similar, with more than 50 per cent of the respondents in the ' $31-40$ ' age group. The majority of respondents were at middle management level in their respective companies.

\subsection{Experience of the respondents}

The distribution for the experience of the respondents is shown in Figure 3.

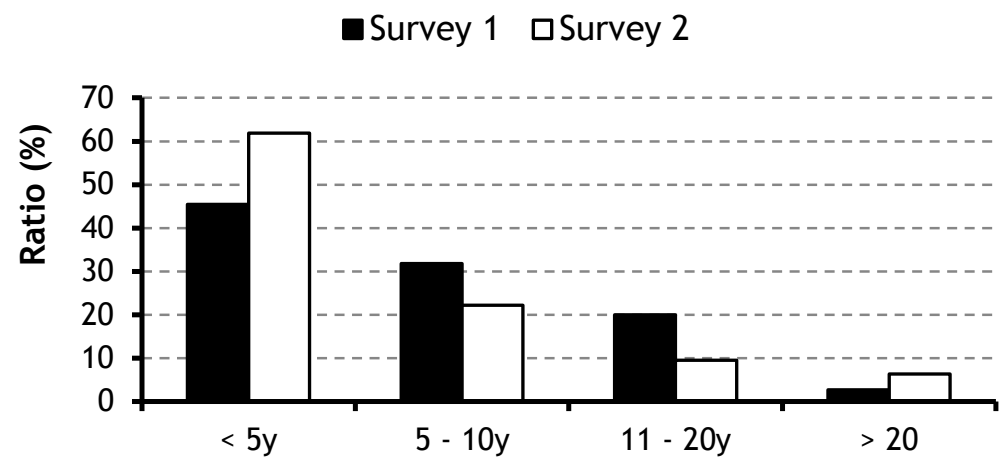

Figure 3: Experience distribution of respondents 
The majority of respondents (> 60\%) for the second survey had less than five years' experience in maintenance or asset management. The average experience for the second survey is therefore slightly less than for the first survey.

\subsection{Designation of respondents}

The designation or managerial level of the respondents for the first survey is indicated in Figure 4. The majority of respondents were in management positions of 'Manager' or 'Supervisor'. This gives some credibility to the results of the survey, since the Asset Management Landscape focuses on management and not on technical disciplines, processes, or actions. The results for different designations were not compared for the first survey.

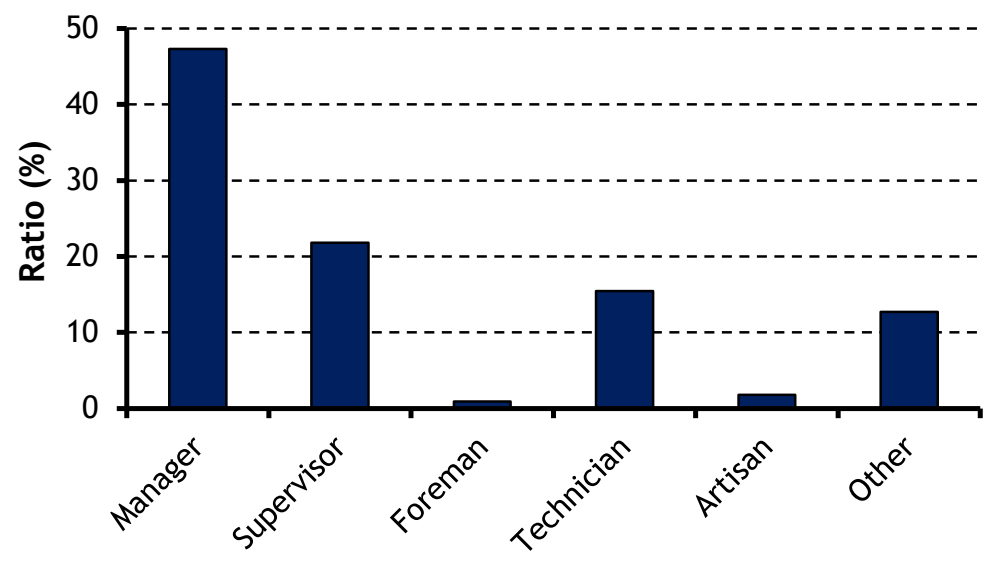

Figure 4: Designation of respondents for the first survey

The designation or managerial level of the respondents for the second survey is indicated in Figure 5 .

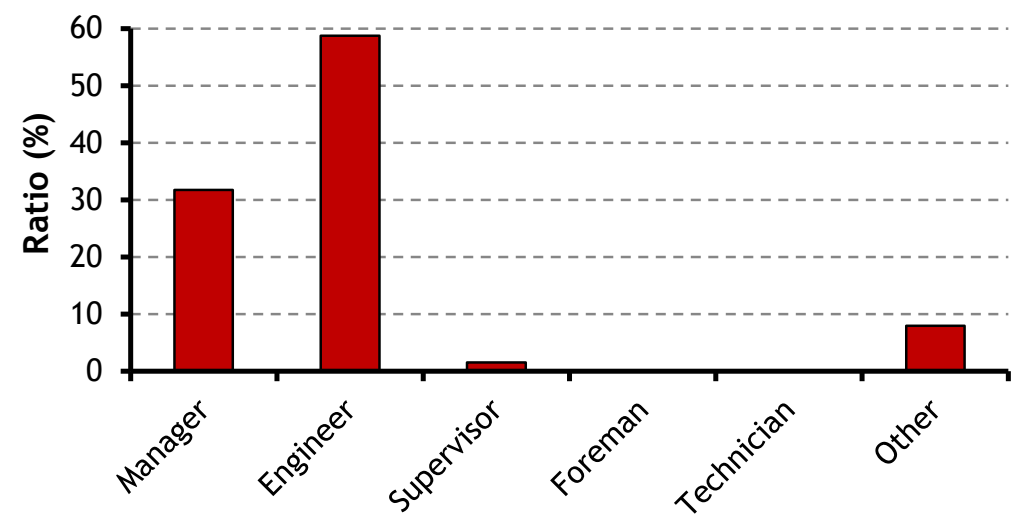

Figure 5: Designation of respondents within organisations

The majority of respondents for the second survey were engineers or managers. The results obtained in the second survey were compared for these two groups: managers and engineers. 


\subsection{Overview}

The mean score and standard deviation were determined for each of the 39 subjects for both surveys. The results are presented in Figures 6 and 7 for the first and second surveys respectively.

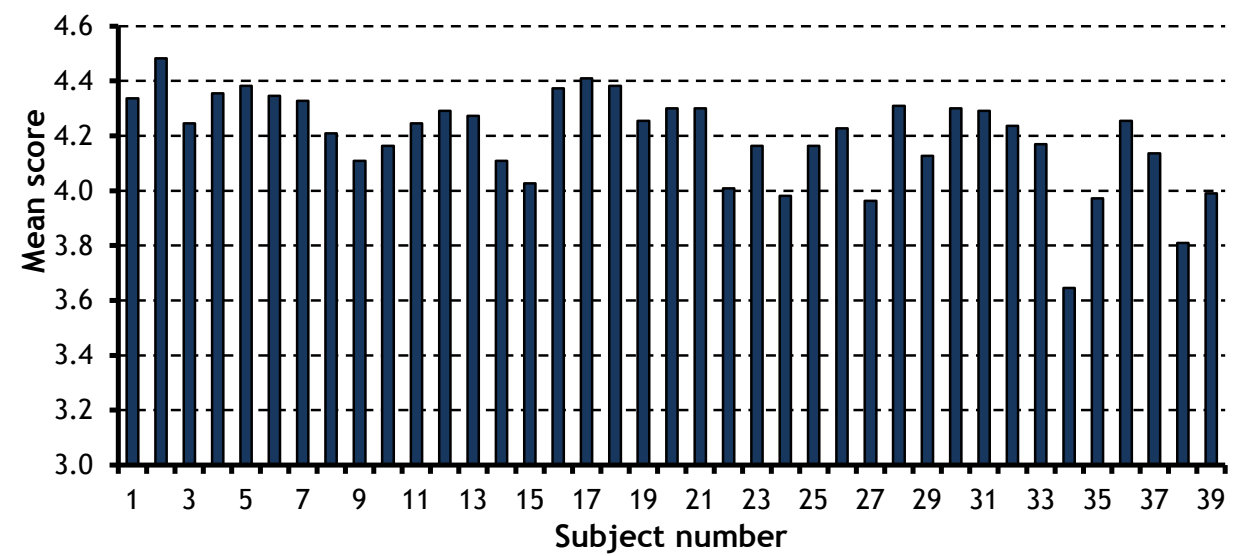

Figure 6: Results for Survey 1 in 2013

The mean values varied from 3.65 for Subject 34 (weather and climate change) to 4.48 for Subject 2 (asset management strategy). The standard deviation values (not indicated in Figures 5 or 6) varied from 0.62 for Subject 3 (demand analysis) to 0.97 for Subject 34 (weather and climate change). The overall average score for all 39 subjects was 4.20.

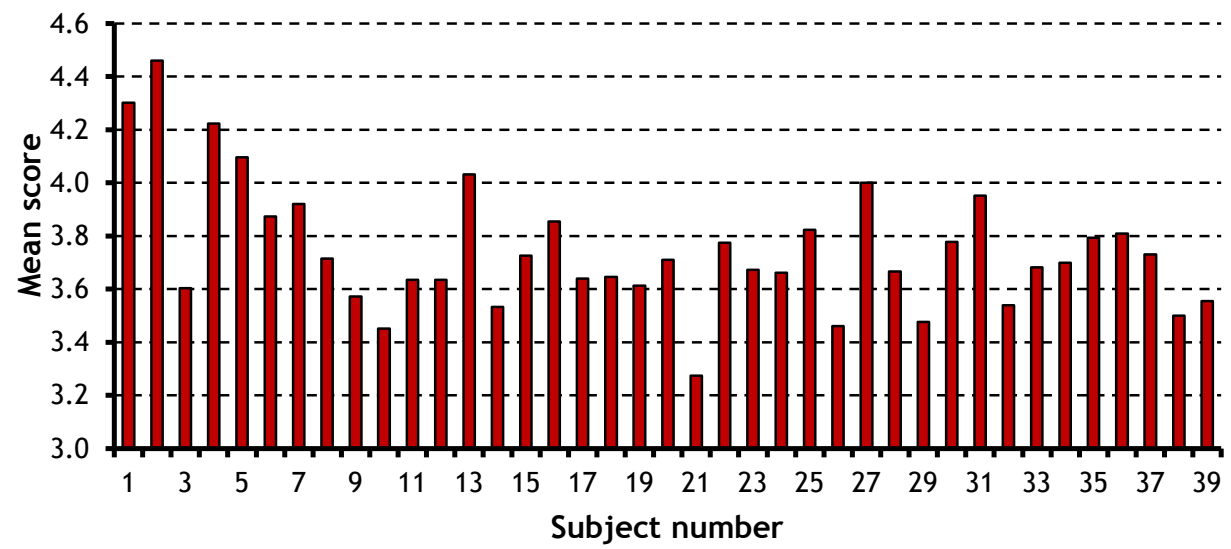

Figure 7: Results for Survey 2 in 2014

The mean values varied from 3.27 for Subject 21 (asset decommissioning and disposal) to 4.46 for Subject 2 (asset management strategy and objectives). The standard deviations varied from 0.70 for Subject 7 (operations and maintenance decision-making) to 1.12 for Subject 21 (asset decommissioning and disposal). The overall average score for all 39 subjects was 3.75 .

The overall average of 3.75 for the second survey is somewhat lower than the overall average of 4.20 for the first survey. Given the standard deviation values for the 39 subjects for both surveys, this difference of 0.45 is not regarded as significant. Thus the individual scores for each subject were not compared for the two surveys. 


\subsection{Most important subjects}

The ten most important subjects for each survey are given in Table 2, with subjects that are common to both lists highlighted in bold text in the second column.

Table 2: The ten most important subjects identified from the two surveys

\begin{tabular}{|c|l|c|l|}
\hline \multicolumn{2}{|l|}{ Top 10 subjects from Survey 1 } & \multicolumn{1}{|c|}{ Top 10 subjects from Survey 2} \\
\hline No. & \multicolumn{1}{|c|}{ Subject name } & 2 & $\begin{array}{l}\text { Subject name } \\
\text { objectives }\end{array}$ \\
\hline 2 & Asset management strategy & 1 & Asset management policy \\
\hline 17 & Reliability engineering & 4 & Strategic planning \\
\hline 18 & Asset operations & 5 & Asset management planning \\
\hline 5 & Asset management plan & 13 & Systems engineering \\
\hline 16 & Maintenance delivery & 27 & Asset management leadership \\
\hline 4 & Strategic planning & 31 & Risk assessment and management \\
\hline 6 & Capital investment decision-making & 7 & $\begin{array}{l}\text { Operations and maintenance decision- } \\
\text { making }\end{array}$ \\
\hline 1 & Asset management policy & 6 & Capital investment decision-making \\
\hline 7 & $\begin{array}{l}\text { Operations and maintenance decision- } \\
\text { making }\end{array}$ & Asset management leadership & Reliability engineering \\
\hline 28 & & & \\
\hline
\end{tabular}

It is noteworthy that eight out of the top ten subjects in the first survey were also indicated in the top ten subjects in the second survey. The survey populations in the two surveys were totally independent, with no respondent completing both surveys. The subjects 'asset management strategy', 'strategic planning', 'asset management policy', and 'asset management planning' all represent the high-level strategic aspects of asset management, and both groups rated these aspects as very important for asset management.

The technical area, 'reliability engineering', features in the top ten for both surveys, but is only ranked tenth in the second survey. The first survey ranked this as second most important, probably since this group comprised more students at lower hierarchical levels in the organisation than in the sample for the second survey. There is a close correlation between 'reliability engineering' and the development of preventive maintenance tactics (operations and maintenance decision-making). It is clear that this process is regarded as very important by the asset management practitioners.

\subsection{Least important subjects}

In addition to analysing the most important subjects to be included in an asset management curriculum, it is also interesting to look at the subjects that were scored lowest. These subjects could either be left out of such a curriculum or be considered as elective modules. The ten least important subjects for each survey are given in Table 3 , with subjects that are common to both lists highlighted in bold text in the second column.

From Table 3, it is clear that the respondents see less value in some subjects, but that these cannot be grouped logically, as was the case with the most important subjects. It is noticeable, however, that these low-rated subjects often deal with non-engineering issues such as supply chain, finance, organisational culture, stakeholder communication, sales, or human resource management. It may be that the respondents viewed these topics as being outside the scope of their technical view of asset management. Nonetheless, it would be advisable for these topics to be elective rather than mandatory modules in an asset management training programme. 
Table 3: The ten least important subjects from the two surveys

\begin{tabular}{|c|l|l|l|}
\hline \multicolumn{2}{|c|}{ Bottom 10 subjects from Survey 1 } & \multicolumn{2}{c|}{ Bottom 10 subjects from Survey 2} \\
\hline No. & \multicolumn{1}{|c|}{ Subject name } & \multicolumn{1}{c|}{ Subject name } \\
\hline 34 & Weather and climate change & 21 & Asset decommissioning and disposal \\
\hline 38 & Accounting practices & 10 & Shutdowns and outage strategy \\
\hline 27 & Contract and supplier management & 26 & $\begin{array}{l}\text { Procurement and supply chain } \\
\text { management }\end{array}$ \\
\hline 35 & Asset change management & 29 & Organisational culture \\
\hline 24 & Asset knowledge standards & 38 & Asset costing and valuation \\
\hline 39 & Stakeholder relations & 14 & Configuration management \\
\hline 22 & Asset rationalisation and disposal & 32 & $\begin{array}{l}\text { Contingency planning and resilience } \\
\text { analysis }\end{array}$ \\
\hline 15 & Configuration management & 39 & Stakeholder engagement \\
\hline 14 & Systems engineering & 9 & Resourcing strategy \\
\hline 9 & Resourcing strategy and optimisation & 3 & Demand analysis \\
\hline
\end{tabular}

\subsection{Subject groups}

The 39 subjects are grouped into six main subject groups. These groups are:

1. Strategy and planning;

2. Asset management decision-making;

3. Lifecycle delivery;

4. Asset information;

5. Organisation and people; and

6. Risk and review.

The average rating per subject group (SG) for the two surveys is shown in Figure 8 .

口Survey 2013 口Survey 2014

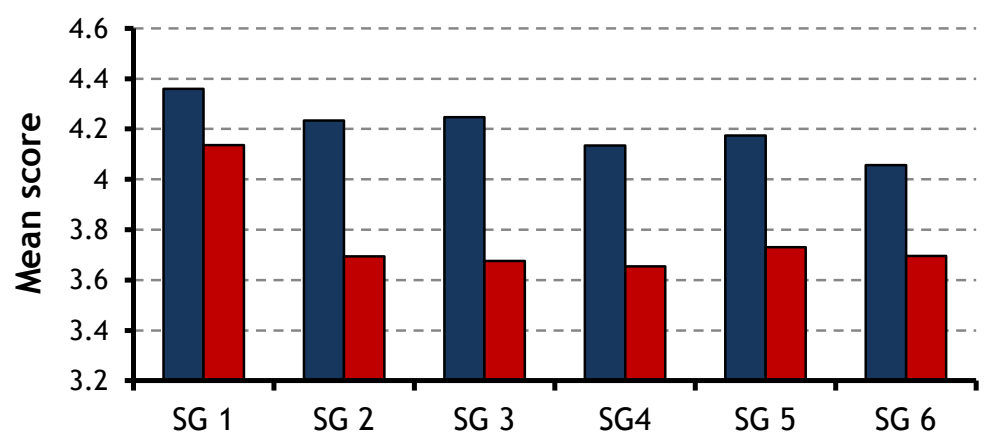

Figure 8: Importance rating per subject group

As seen in Figure 8, the 'strategy and planning' subject group scored significantly higher than the other five groups, especially in the 2014 survey. There is no significant difference among the other five subjects groups for both surveys. More than 50 of the 63 respondents for this survey were Masters' students in Engineering Management. Many of these students are employed in middle management in their respective organisations, and are therefore often involved in policy-making and strategic planning. It could be expected that they would value these areas as most important in asset management. 


\subsection{Influence of age, experience, and job position}

The questionnaires collected ordinal data for the purpose of ranking the 39 subjects. The data is therefore not suitable for extensive parametric analysis. The parametric analyses that were done on the data and reported in this section were more for interest, and did not contribute in a meaningful way to the final results of determining the subjects or knowledge areas that should be covered in future curricula on asset management or engineering management.

\subsubsection{Influence of age}

Respondents of different age groups might feel differently about the importance of some of the 39 subjects. The distribution for the four age groups is shown in Figure 2 . The number of respondents for the age groups that were younger than 25 years and older than 40 years are small, and the average scores were therefore determined for two age groups only: all those aged 30 years or younger, and all those older than 30 years. The mean values and standard deviation values for the subjects with the largest difference in mean value are presented in Table 4.

Table 4: Analysis for five subjects with the largest difference in mean values for two age groups

\begin{tabular}{|c|c|c|c|c|c|c|}
\hline \multirow{2}{*}{ No. } & \multicolumn{2}{|c|}{ Age $\leq 30$ years } & \multicolumn{2}{c|}{ Age $>\mathbf{3 0}$ years } & \multirow{2}{*}{ Difference in means } & p-value \\
\cline { 2 - 5 } & Mean & Std. Dev. & Mean & Std. Dev. & & \\
\hline 14 & 3.32 & 0.97 & 3.65 & 0.95 & -0.33 & 0.570 \\
\hline 30 & 3.55 & 0.89 & 3.90 & 0.83 & -0.36 & 0.060 \\
\hline 24 & 3.36 & 0.98 & 3.83 & 1.08 & -0.46 & 0.435 \\
\hline 21 & 2.86 & 1.10 & 3.50 & 1.06 & -0.64 & 0.072 \\
\hline 6 & 4.14 & 0.87 & 3.73 & 0.92 & +0.40 & 0.039 \\
\hline
\end{tabular}

An independent sample t-test (T-TEST function of MS Excel) was performed on the two data sets of the two age groups. The two data sets were not tested for normality; but the t-test is described as a robust test with respect to the assumption of normality. This means that even deviations away from normality do not have a large influence on the results and error rates [16]. The exception to this is if the ratio of the size of the larger group versus the size of the smaller group is more than 1.5. The age group younger than 30 years had 21 data points, and the group older than 30 years had 40 data points. A random selection of nine data points from the older group was done using the RANDBETWEEN function in MS Excel and deleted from the data set so that the size difference was within the required range.

The p-values from the independent sample t-test for the five subjects with the largest difference in mean values are shown in Table 4 . The p-values for four subjects are more than 0.05 ; therefore mean values for the two age groups do not differ significantly at a confidence level of 95 per cent. However, the p-value for Subject 6 is 0.039 , which is less than 0.05; therefore the null hypothesis (the distributions do not differ significantly) cannot be accepted, and the alternative hypothesis should be accepted. Subject 6 , "capital investment decision-making', is in the top ten for both surveys, but the younger group deem it more important than do the older group.

\subsubsection{Influence of experience}

The distribution of experience groups is shown in Figure 2. Due to small numbers for the higher experience groups, only two groups were analysed. The mean values and standard deviation were determined for all respondents with less than five years' experience ( 38 respondents), as well as for those with more than five years' experience (23 respondents). The values are shown in Table 5. 
Table 5: Analysis for five subjects with the largest difference in mean values for two experience groups

\begin{tabular}{|c|c|c|c|c|c|c|}
\hline \multirow{2}{*}{ No. } & \multicolumn{2}{|c|}{ Experience $\leq \mathbf{5}$ years } & \multicolumn{2}{c|}{ Experience $>$ 5 years } & \multirow{2}{*}{ Mean difference } & p-value \\
\cline { 2 - 5 } & Mean & Std. Dev. & Mean & Std. Dev. & & \\
\hline 30 & 3.62 & 0.62 & 4.04 & 0.69 & -0.43 & 0.025 \\
\hline 21 & 3.08 & 1.21 & 3.58 & 1.14 & -0.50 & 0.116 \\
\hline 17 & 3.45 & 0.64 & 3.96 & 0.71 & -0.51 & 0.377 \\
\hline 24 & 3.45 & 0.94 & 4.00 & 1.02 & -0.55 & 0.029 \\
\hline 13 & 4.21 & 1.16 & 3.75 & 0.99 & +0.46 & 0.076 \\
\hline
\end{tabular}

Three data points were deleted randomly from the data set for the group with less than five years' experience, in order to ensure that the size of the larger group was not more than 1.5 times the size of the smaller group. The RANDBETWEEN function of MS Excel was used to achieve this.

The p-values from the independent sample t-test for subjects 13,17, and 21 are more than 0.05; therefore the mean values for the two experience groups do not differ significantly at a 95 per cent confidence level. The p-values for Subject 24 (asset information systems) and Subject 30 (competence management) are less than 0.05 , and the mean value for these two subjects therefore differs significantly at a 95 per cent confidence level. The group with more than five years' experience valued these two subjects much higher than the less experienced age group. The more experienced group probably have practical experience of the value of a good information system for managing assets and of the value of developing the competency of asset management practitioners and artisans.

\subsubsection{Influence of job position}

Job position might be related to age and/or experience, but the mean scores and standard deviations were also determined for the two groups that were most represented in the sample of the second survey: managers (20 respondents) and engineers ( 37 respondents). The results are shown in Table 6.

Table 6: Analysis for five subjects with the largest difference in mean values for two job designations

\begin{tabular}{|c|c|c|c|c|c|c|}
\hline \multirow{2}{*}{ No. } & \multicolumn{2}{|c|}{ Managers } & \multicolumn{2}{c|}{ Engineers } & \multirow{2}{*}{$\begin{array}{c}\text { Difference in } \\
\text { means }\end{array}$} & p-value \\
\cline { 2 - 6 } & Mean & Std. Dev. & Mean & Std. Dev. & -0.34 & 0.216 \\
\hline 33 & 3.50 & 0.92 & 3.84 & 0.87 & -0.35 & 0.222 \\
\hline 17 & 3.40 & 1.02 & 3.75 & 0.85 & -0.43 & 0.247 \\
\hline 10 & 3.15 & 0.96 & 3.58 & 1.00 & -0.45 & 0.212 \\
\hline 6 & 3.60 & 1.02 & 4.05 & 0.85 & +0.39 & 0.099 \\
\hline 14 & 3.80 & 1.08 & 3.41 & 0.90 & & \\
\hline
\end{tabular}

Seven data points were deleted randomly from the data set for the engineers group in order to ensure that the size of the larger group was not more than 1.5 times the size of the smaller group. The RANDBETWEEN function of MS Excel was used to achieve this.

The $p$-values from the independent sample t-test for the five subjects in Table 6 are more than 0.05; therefore the distributions for managers and engineers for these five subjects (and all the others) do not differ significantly at a 95 per cent confidence level. 


\subsection{Benefit of the Landscape documents}

A last question posed to respondents in the second survey only was: "What would you regard as the biggest advantage or benefit of the Landscape 2 document and its 39 subjects on asset management?"

Respondents could select one of six options provided. The results of this question could assist service providers in marketing the ISO 55000 asset management standard, as well as the GFMAM Landscape 2 document, to asset owners. The results are shown in Figure 9.

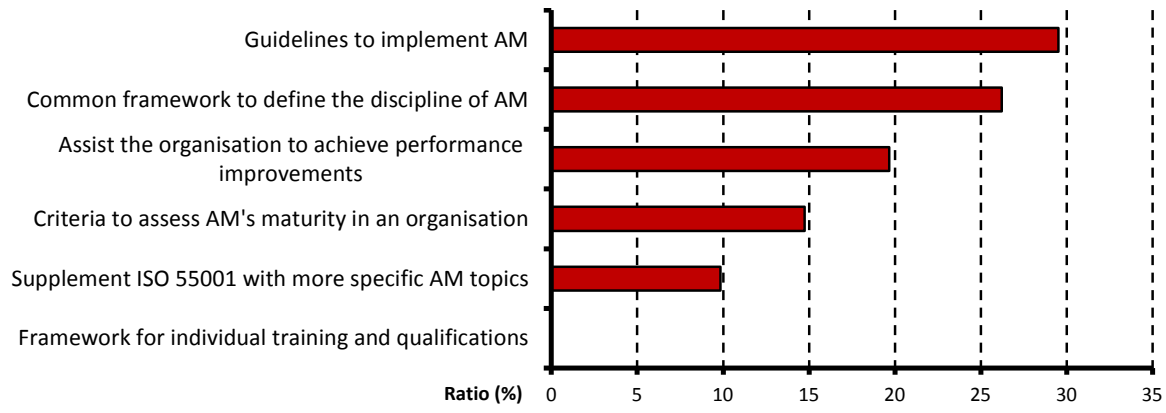

Figure 9: Respondents' opinion of the benefits of the Landscape 2 document

From Figure 9, it appears that the most important benefits of the Landscape 2 document are that it will be used as 'guidelines to implement asset management' and as a 'common framework to define the discipline of asset management'. This document can therefore make a valuable contribution towards education and the practical implementation of frameworks such as ISO 55000 and the Landscape 2 document.

\section{CONCLUSION}

Samples were taken from postgraduate students doing an Honours or Masters degree in Engineering Management. The data was interpreted specifically with the aim of determining the importance of the 39 subjects when compiling postgraduate courses in asset management. Since the objective of the analysis was focused, it makes sense to use a nonprobable sample of postgraduate engineering students. It does mean, however, that the results cannot be used to rank the importance of these subjects outside of this context.

The 39 subjects proposed by the GFMAM's Landscape documents cover quite a large area, which might make it impractical to include all of them in a single asset management course or qualification. It would therefore be advisable to cover the most important subjects as mandatory subjects, while leaving out others - or at least giving students the choice of which ones to include.

The study provided very useful information to assist training providers or academic institutions in compiling a curriculum for an asset management training course. The following conclusions can be drawn from the results of the study:

- the 'asset management strategic planning process' was regarded as the most important area, covering topics such as policy, strategy, objectives, and detailed plans. The underpinning strategic planning process should also be covered;

- the 'development of maintenance tactics' based on the inherent reliability of the equipment was also viewed as very important;

- ' 'maintenance delivery' received a strong vote, as was expected, but it was surprising that 'shutdown and outage strategy' was regarded as unimportant;

- ' 'asset operations' remains a critical part of any asset management process;

- 'capital project management' was regarded as a high priority, especially 'upfront system engineering' and 'capital investment decision-making'. It was interesting that 'decommissioning of old assets' was viewed as unimportant by the respondents; 
- $\quad$ all of the new asset management frameworks (PAS 55, ISO 55000 , and the Asset Management Landscape) place a high value on 'risk management'; and this was echoed by the participants of the survey; and

- finally, as can be expected, the role of 'effective leadership' in the success of asset management was also recognised.

The participants viewed many of the non-engineering topics as non-core or unimportant. So it would be advisable to leave them as part of other training courses, or at best, to include them as elective modules. These include:

- $\quad$ procurement and supply chain management;

- organisational culture;

- $\quad$ asset costing and valuation;

- configuration management;

- $\quad$ stakeholder engagement; and

- resourcing strategy and resource management.

It was encouraging to see that the participants valued the 39 subjects as a framework to define asset management better and as a guide to implement it in organisations.

\section{REFERENCES}

[1] Global Forum on Maintenance and Asset Management (GFMAM). 2014. The asset management landscape. $2^{\text {nd }}$ edition. Retrieved from http://www.gfmam.org. Accessed on 8 March 2015.

[2] International Organization for Standardization. 2008. ISO 9001 - Quality management systems Requirements. Retrived from http://www.iso.org/iso/iso_9000 (Accessed on 23 March 2015).

[3] International Organization for Standardization. 2008 ISO/TS 16949 - Automotive quality management standard. Retrieved from http://www. iso.org/iso/catalogue_detail?csnumber=52844 (Accessed on 23 March 2015).

[4] British Standards Institute. BS OHSAS. 2000. 18000 - Occupational health and safety management systems specification. Retrieved from http://www.bsigroup.com/en-GB/ohsas18001-occupational-health-and-safety/ (Accessed on 23 March 2015).

[5] International Organization for Standardization. 2004. ISO 14001 - Environmental management systems. Retrieved from http://www. iso.org/iso/iso14000 (Accessed on 23 March 2015).

[6] International Organization for Standardization. 2009. ISO 31000 - Risk management - Principles and guidelines. Retrieved from http://www. iso.org/iso/home/standards/iso31000.htm (Accessed on 23 March 2015).

[7] Geraerds, W.M.J. 1992. The EUT maintenance model. International Journal of Production Economics, 24 (3), pp. 209-216.

[8] Márques, A.C. 2007. The maintenance management framework: Models and methods for complex systems maintenance. London: Springer-Verlag.

[9] Visser, J.K. 1997. A conceptual framework for understanding and teaching maintenance. Mechanical Engineering Transactions, ME22 (3\&4), pp. 61-69.

[10] New Zealand Asset Management Support (NAMS). 2011. International Infrastructure maintenance manual. Retrieved from http://www.nams.org.nz/pages/273/internationalinfrastructure-management-manual-2011-edition.htm (Accessed on 23 March 2015).

[11] International Organization for Standardization. 2014. ISO 55001 - Asset management Management systems - Requirements. Retrieved from

http: / / www. iso.org/iso/catalogue_detail?csnumber=55089 (Accessed on 23 March 2015).

[12] British Standards Institute (BSI). PAS 55:2008 - Publicly available specification. Retrieved from http:/ /www.bsigroup.com. (Accessed on 6 March 2015).

[13] Deming, W.E. 1993.The New Economics. Massachusets Institute of Technology Press. Cambridge, MA, pp 135.

[14] Institute for Asset Management (IAM). 2011. Asset management - An anatomy. Retrieved from http://www.thelAM. org. Accessed on 6 March 2015.

[15] Asset Management Council. 2010. Asset management body of knowledge (AMBoK). Retrieved from http://www.amcouncil.com.au/asset-management-body-of-knowledge. html (Accessed on 6 March 2015).

[16] Lund Research Ltd. 2013. Laerd statistics: Independent T-test for two samples. Retrieved from https://statistics.laerd.com/statistical-guides/independent-t-test-statistical-guide.php (Accessed on 6 March 2015). 